\title{
INTOXICAÇÃO EXPERIMENTAL POR Phytolacca decandra EM OVINOS ${ }^{1}$
}

\author{
EXPERIMENTAL POISONING BY Phytolacca decandra IN SHEEP
}

\author{
Roselene Ecco $^{2}$ Claudio Severo Lombardo de Barros ${ }^{3}$ Luiz Francisco Irigoyen ${ }^{4}$
}

RESUMO

Doses únicas de 10 a $25 \mathrm{~g} / \mathrm{kg}$ das folhas verdes de Phytolacca decandra foram administradas oralmente a 11 ovinos. Dois desses ovinos $(20$ e $25 \mathrm{~g} / \mathrm{kg}$ ) morreram 6 horas após a ingestão da planta e os outros nove adoeceram levemente e se recuperaram. Um outro ovino recebeu 4 doses diárias de $5 \mathrm{~g} / \mathrm{kg}$ da mesma planta. Esse ovino e outros dois usados como controles não adoeceram. Os principais sinais clínicos nos ovinos afetados foram dor abdominal, inquietação, manoteio, distúrbios respiratórios, tremores e hiperestesia. As alterações macroscópicas mais importantes em dois ovinos necropsiados estavam restritas ao sistema digestivo e consistiam de avermelhamento difuso da mucosa do rúmen, retículo, abomaso e intestino delgado. Microscopicamente, as alterações eram necrose de coagulação e microabscessos na mucosa dos pré-estômagos e presença de numerosos cristais birrefringentes na luz dos túbulos renais.

Palavras-chave: Phytolacca decandra, plantas tóxicas, doenças de ovinos.

\section{SUMMARY}

Single dosis varying from 10 to $25 \mathrm{~g} / \mathrm{kg}$ of fresh green leaves of Phytolacca decandra were orally force fed to 11 sheep. Two of these sheep (20 and $25 \mathrm{~g} / \mathrm{kg}$ ) died 6 hours after the ingestion of the plant and the other 9 got mildly sick and recovered. Another sheep was fed 4 daily dosis of $5 \mathrm{~g} / \mathrm{kg}$ of the same plant. This sheep and another two used as controls did not get sick. The main clinical signs in the affected sheep were abdominal pain, restless, pawing, respiratory distress, muscle tremors, and hyperesthesia. Gross findings in the two necropsied sheep were confined to the digestive tract and consisted of diffuse mucosal reddening of the rumen, reticulum, abomasum, and small intestine. Microscopic changes were coagulative necrosis and microabscesses in the mucosa of the forestomachs and several intratubular birefringent crystals in the kidney.
Key words: Phytolacca decandra, poisonous plants, diseases of sheep.

\section{INTRODUÇÃO}

Phytolacca decandra $($ sin. $=$ P. americana, nome comum caruru do campo) é uma planta herbácea ou subarbustiva da família Phytolaccaceae, nativa do continente americano (Figura 1). Ocorre desde os Estados Unidos até a Argentina e está distribuída por todo o Brasil, principalmente nas regiões Nordeste, Sudeste e Sul (LORENZI, 1991). A intoxicação por $\boldsymbol{P}$. decandra tem sido descrita em bovinos (KINGSBURY \& HILLMAN, 1964) eqüinos (OEHME, 1994), suínos (PATTERSON, 1929), ovinos (MUGERA, 1970; PEIXOTO et al., 1997), aves (BARNETT, 1975; FRASER, 1991) e humanos (KINGSBURY \& HILLMAN, 1964).

Os sinais clínicos da intoxicação incluem, nas diversas espécies, cólica, diarréia (KINGSBURY \& HILLMAN, 1964; PEIXOTO $\boldsymbol{e t}$ al., 1997), hipotermia, insuficiência respiratória e convulsões (FRASER, 1991; OEHME, 1994). Na necropsia de ruminantes, há avermelhamento da mucosa do rúmen, retículo e intestino (STORIE $\boldsymbol{e t}$ al.,1992; PEIXOTO et al., 1997). Microscopicamente, ocorre necrose de coagulação da mucosa do rúmen e retículo e cristais nos túbulos dos rins e na mucosa do rúmen (PEIXOTO et al., 1997). Os princípios tóxicos identificados em $\boldsymbol{P}$. decandra são

\footnotetext{
${ }^{1}$ Parte da Dissertação de Mestrado do primeiro autor apresentada ao Programa de Pós-graduação em Medicina Veterinária da Universidade Federal de Santa Maria (UFSM). Projeto financiado pelo CNPq-PRONEX.

${ }^{2}$ Médico Veterinário. Aluno do Programa de Pós-graduação em Medicina Veterinária ,UFSM.

${ }^{3}$ Médico Veterinário, PhD., Professor Titular, Departamento de Patologia, UFSM.

${ }^{4}$ Médico Veterinário, PhD., Professor Adjunto, Departamento de Patologia, UFSM, 97105-900 Santa Maria, RS. E-mail gabirigo@lince.hcv.ufsm.br. Autor para correspondência.
} 


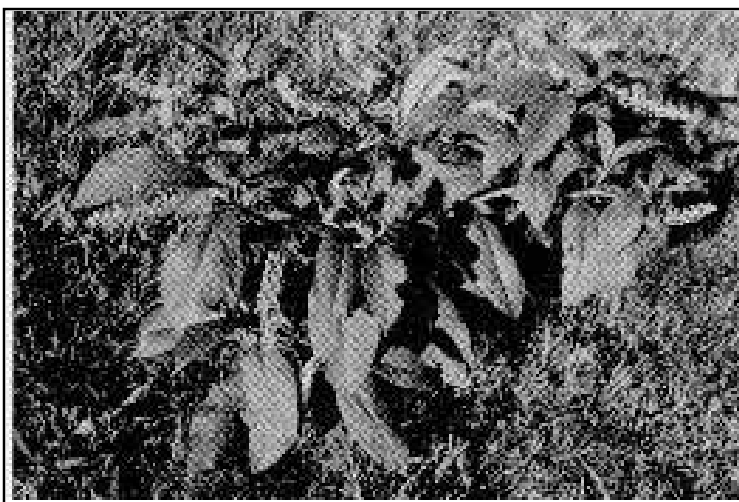

Figura 1 - Espécime adulto de Phytolacca decandra. Fotografia tomada em dezembro no município de Itaara, RS.

fitolacotoxina, fitolacina e ácido oxálico (McCAIN et al. 1985; OEHME, 1994). A única documentação da intoxicação por $\boldsymbol{P}$. decandra no Brasil relata a toxicose em ovinos no Rio Grande do Sul (PEIXOTO et al., 1997).

Este trabalho teve como objetivo reproduzir experimentalmente a intoxicação por $\boldsymbol{P}$. decandra em ovinos, determinar o quadro clínicopatológico da toxicose, a dose tóxica e verificar se a planta possui efeito acumulativo.

\section{MATERIAL E MÉTODOS}

$P$. decandra foi colhida no município de Itaara, RS, onde havia ocorrido um surto da intoxicação em ovinos (PEIXOTO et al., 1997). Até ser administrada aos animais, a planta foi mantida refrigerada por um período máximo de 5 dias. Quatorze ovinos foram mantidos, durante o experimento, numa ração comercial, feno de alfafa e água à vontade. Desses, doze ovinos receberam a planta, em diferentes estágios de desenvolvimento, por administração oral forçada e dois serviram como controles (Tabela 1).

O exame clínico dos ovinos foi realizado a cada 30 minutos após a administração da planta, durante o primeiro dia, e quatro vezes ao dia nos dias subseqüentes, até o fim do experimento. Dois ovinos que tiveram morte espontânea foram necropsiados. Amostras de vários órgãos foram fixadas em formol a $10 \%$ e processadas rotineiramente para histopatologia.

\section{RESULTADOS}

O desfecho clínico do experimento consta na tabela 1. Dois ovinos (1 e 7) que receberam 20 e $25 \mathrm{~g} / \mathrm{kg}$ de folhas jovens de $\boldsymbol{P}$. decandra, colhidaS em outubro e novembro, morreram 6 horas após a administração da planta. Os sinais clínicos iniciavam 1 a 3 horas após o término da administração da planta e se caracterizavam principalmente por apatia, forte dor abdominal, aumento gradativo das freqüências cardíaca e respiratória e sialorréia. A seguir, ocorriaM avermelhamento das mucosas oral e ocular e respiração laboriosa. Os animais apoiavam a cabeça na parede da baia e, ocasionalmente, erguiam os membros anteriores inclinando o pescoço e a cabeça para trás. Manoteio e alternância dos membros, quando em estação foram também observados. Quatro horas após o início dos sinais clínicos, os ovinos mostravam dificuldade para se manter em pé, ficando em estação apenas quando forçados, logo deitavam em decúbito esternal e inclinavam a cabeça em direção ao flanco. Na fase final da doença, ocorriaM dispnéia acentuada, gemidos, espuma na boca, lacrimejamento, tremores musculares constantes, hiperestesia, principalmente na região abdominal, e movimentos de pedalagem.

Os ovinos de 4 a 12, que receberam quantidades variáveis $(10$ a $25 \mathrm{~g} / \mathrm{kg}$ ) de folhas jovens e/ou maduras, colhidas em novembro ou dezembro, mostraram sinais clínicos leves, caracterizados por perda do apetite e amolecimento das fezes. Os sinais iniciavam 4 a 30 horas após a administração da planta e duravam de 24 a 48 horas. O ovino que recebeu 4 administrações diárias de $5 \mathrm{~g} / \mathrm{kg}$ de folhas jovens de $\boldsymbol{P}$. decandra, colhidas em outubro, e os dois controles, não adoeceram.

Na necropsia dos ovinos 1 e 7, observouse que o rúmen e retículo continham folhas não digeridas de $\boldsymbol{P}$. decandra misturadas a grande quantidade de líquido. A mucosa do rúmen estava avermelhada principalmente nos sacos dorsal e ventral, próximo aos pilares e à cárdia. As mucosas do retículo e abomaso estavam difusamente avermelhadas. No abomaso havia, ainda, sufusões distribuídas irregularmente na mucosa, muitas vezes cobertas por pequenos coágulos. A mucosa do duodeno e da porção inicial do jejuno estava avermelhada, com numerosas petéquias, e o conteúdo intestinal era avermelhado. No reto, as fezes apareciam bem formadas e recobertas por muco. Na superfície de corte dos rins, as camadas cortical e medular apresentavam estriações radiadas e brancacentas. Os pulmões de ambos os ovinos estavam difusamente vermelhoescuros, edematosos e com crepitação diminuída.

As principais alterações microscópicas tinham intensidades semelhantes nos dois ovinos necropsiados e localizavam-se na mucosa do rúmen e retículo. Nos estratos córneo e granuloso, havia degeneração vacuolar, com formação de vesículas, e necrose de coagulação focal, ocasionalmente associadas a colônias bacterianas. Numerosos microabscessos eram vistos no epitélio de revestimento e, em 
Tabela 1 - Intoxicação experimental por Phytolacca decandra em ovinos.

\begin{tabular}{|c|c|c|c|c|c|c|}
\hline Ovino & $\begin{array}{r}\text { Dose } \\
(\mathrm{g} / \mathrm{kg})\end{array}$ & $\begin{array}{l}\text { Parte da planta } \\
\text { administrada }\end{array}$ & $\begin{array}{l}\text { Época da } \\
\text { colheita }\end{array}$ & $\begin{array}{l}\text { Estádio da planta } \\
\text { administrada }\end{array}$ & Local da colheita & Desenlace clínico \\
\hline 1 & 20 & Folhas jovens & Outubro & Início da floração & Área cultivada & Morreu \\
\hline 2 & 10 & Folhas jovens & Outubro & Início da floração & Área cultivada & Adoeceu levemente \\
\hline 3 & $20(4 \times 5)^{*}$ & Folhas jovens & Outubro & Início da floração & Área cultivada & Não adoeceu \\
\hline 4 & 10 & $\begin{array}{l}\text { Folhas jovens + } \\
\text { folhas maduras }\end{array}$ & Novembro & $\begin{array}{l}\text { Adulta com } \\
\text { inflorescência }\end{array}$ & Área cultivada & Adoeceu levemente \\
\hline 5 & 15 & $\begin{array}{l}\text { Folhas jovens }+ \\
\text { folhas maduras }\end{array}$ & Novembro & $\begin{array}{l}\text { Adulta com } \\
\text { inflorescência }\end{array}$ & Área cultivada & Adoeceu levemente \\
\hline 6 & 20 & $\begin{array}{l}\text { Folhas jovens }+ \\
\text { folhas maduras }\end{array}$ & Novembro & $\begin{array}{c}\text { Adulta com } \\
\text { inflorescência }\end{array}$ & Área cultivada & Adoeceu levemente \\
\hline 7 & 25 & Folhas jovens & Novembro & $\begin{array}{l}\text { Adulta com } \\
\text { inflorescência }\end{array}$ & Área cultivada & Morreu \\
\hline 8 & 25 & Folhas maduras & Novembro & $\begin{array}{l}\text { Adulta com } \\
\text { inflorescência }\end{array}$ & Área cultivada & Adoeceu levemente \\
\hline 9 & 15 & Folhas jovens & Dezembro & $\begin{array}{l}\text { Adulta com } \\
\text { inflorescência }\end{array}$ & Área não cultivada & Adoeceu levemente \\
\hline 10 & 15 & Folhas jovens & Dezembro & $\begin{array}{l}\text { Adulta com } \\
\text { inflorescência }\end{array}$ & Área não cultivada & Adoeceu levemente \\
\hline 11 & 20 & Folhas jovens & Dezembro & $\begin{array}{c}\text { Adulta com } \\
\text { inflorescência }\end{array}$ & Área não cultivada & Adoeceu levemente \\
\hline 12 & 25 & Folhas jovens & Dezembro & $\begin{array}{l}\text { Adulta com } \\
\text { inflorescência }\end{array}$ & Área não cultivada & Adoeceu levemente \\
\hline 13 & controle & - & & & & Não adoeceu \\
\hline 14 & controle & - & & & & Não adoeceu \\
\hline
\end{tabular}

* recebeu a dose total de $20 \mathrm{~g} / \mathrm{kg}$ dividida em quatro doses de $5 \mathrm{~g} / \mathrm{kg} / \mathrm{dia}$.

certos pontos, havia clivagem do epitélio superficial com separação dos estratos córneo e granuloso dos estratos espinhoso e basal. Na mucosa do omaso, as lesões eram semelhantes, porém mais leves. No abomaso, havia edema e congestão moderados na mucosa e submucosa, com leve infiltração neutrofílica e perda de células epiteliais. No intestino delgado e cólon, foram observados edema e congestão da mucosa e submucosa, necrose focal do epitélio intestinal e leve infiltrado neutrofílico e histiocitário na mucosa. Essas lesões eram mais acentuadas no duodeno e jejuno. Nos rins, havia leve degeneração do epitélio dos túbulos contorcidos proximais e distais, com formação de cilindros hialinos e presença de numerosos cristais birrefringentes morfologicamente compatíveis com oxalato. Havia congestão e seqüestração de neutrófilos nos capilares dos alvéolos pulmonares e edema pulmonar moderado.

\section{DISCUSSÃO}

$\boldsymbol{P}$. decandra demonstrou-se tóxica para ovinos. O quadro clínico-patológico apresentado pelos animais foi semelhante ao descrito na intoxicação por $\boldsymbol{P}$. decandra em ovinos (MUGERA, 1970; PEIXOTO et al., 1997). A menor dose que causou doença foi de $10 \mathrm{~g} / \mathrm{kg}$ da planta colhida em outubro e a menor dose que causou a morte foi a de $20 \mathrm{~g} / \mathrm{kg}$ da planta colhida também em outubro. A mesma quan- tidade $(20 \mathrm{~g} / \mathrm{kg})$ e mesmo tipo de material de planta (folhas jovens), colhido na mesma época, quando administrado em quatro doses diárias de $5 \mathrm{~g} / \mathrm{kg}$, não causou sinais clínicos, indicando que não existe um efeito acumulativo. A planta colhida em novembro e dezembro causou apenas alterações clínicas leves quando administrada a ovinos em doses entre $10 \mathrm{e}$ $25 \mathrm{~g} / \mathrm{kg}$.

Aparentemente, o princípio ativo está mais concentrado nas partes tenras da planta e sofre modificação sazonal, pois a maior toxicidade estava presente nas folhas da planta nos meses de outubro e novembro, diminuindo no final da primavera, ao contrário da noção de que a planta possui a mesma toxidez todo o ano (McCAIN et al. 1985). Neste experimento, a época de colheita da planta e seu ciclo vegetativo podem ter influenciado a ocorrência da intoxicação e é possível que as condições do solo tenham influência na concentração do princípio ativo na planta. Nas primeiras colheitas, as plantas foram retiradas de uma área cultivada e, nas colheitas seguintes, foram retiradas de solos não cultivados recobertos por gramínea (Paspalum spp).

Os sinais clínicos observados nos ovinos neste experimento, como pressão da cabeça contra a parede, foram interpretados como manifestações de cólica. Embora sinais clínicos atribuídos a distúrbios neurológicos centrais tenham sido descritos na intoxicação por Phytolacca decandra (PEIXOTO et al., 
1997), eles não ocorreram nos ovinos deste experimento e não se observaram lesões do encéfalo nos dois ovinos necropsiados. A diarréia, descrita na intoxicação por $\boldsymbol{P}$. decandra em ovinos (MUGERA, 1970) tampouco foi observada nos animais deste experimento.

Secreção nasal seromucosa e respiração laboriosa, principalmente no estágio final da doença, foram observadas nos ovinos que morreram. Propriedades tóxicas irritantes para o sistema digestivo e respiratório têm sido descritas em $\boldsymbol{P}$. decandra (MUGERA, 1970), mas edema e hemorragia pulmonares, descritos nessa intoxicação em ovinos (MUGERA, 1970), não foram encontrados nos animais deste experimento. Tem sido descrito que a fitolacotoxina contida na planta causa anemia generalizada (OEHME, 1994). Embora hemogramas não tenham sido realizados nos animais deste experimento, não houve alterações clínicas ou de necropsia sugestivas de anemia.

As alterações de necropsia mais importantes consistiam, principalmente, de avermelhamento difuso da mucosa dos pré-estômagos e planta não digerida, reconhecida como $\boldsymbol{P}$. decandra, no rúmen, misturada a grande quantidade de líquido. Avermelhamento da mucosa do rúmen e, em menor grau, do retículo, foi relatado na intoxicação espontânea por $\boldsymbol{P}$. decandra (PEIXOTO et al., 1997). Em casos naturais de intoxicações por plantas que causam morte rápida, como Prunus sellowii (GAVA, 1993), a presença da planta não digerida no rúmen é um forte indício da etiologia.

Uma rumenite tóxica aguda foi a principal alteração observada nos dois ovinos necropsiados. Alterações semelhantes foram descritas na intoxicação por $\boldsymbol{P}$. decandra em ovinos (MUGERA, 1970; PEIXOTO et al., 1997). A lesão é semelhante à causada por outras plantas tóxicas como Baccharis spp. (TOKARNIA et al., 1992; BARROS, 1993) e Baccharidastrum triplinervium (LANGOHR et al., 1999).

No rúmen, retículo e abomaso não foram observados os cristais birrefringentes como os descritos anteriormente na intoxicação por $\boldsymbol{P}$. decandra em ovinos (PEIXOTO et al. 1997). A participação desses cristais semelhantes a oxalato na patogenia das lesões gástricas é incerta, já que as lesões gástricas são atribuídas a saponinas (LEWIS \& SMITH, 1979). P decandra contém ácido oxálico (McCAIN et al., 1985) e os cristais birrefringentes observados nos túbulos renais dos ovinos necropsiados podem ser atribuídos à presença dessa substância na planta, embora a participação dessa alteração renal no quadro clínico seja, no mínimo, incerta, pois não era associada a lesões degenerativas que justificassem insuficiência renal.
A planta parece ser pouco palatável e a ingestão só ocorre quando há carência alimentar (KINGSBURRY \& HILLMAN, 1964; PEIXOTO $\boldsymbol{e t}$ $\boldsymbol{a l}$., 1997). Sendo assim, P. decandra tem uma importância econômica pequena e os proprietários devem ser alertados para evitar o acesso dos animais à planta quando houver escassez de forragem.

\section{REFERÊNCIAS BIBLIOGRÁFICAS}

BARNETT, B.D. Toxicity of pokeberries (fruit of Phytolacca americana Large) for turkey poults. Poult Sci, v.54, n.4, p.1215-1217, 1975 .

BARROS, C.S.L. Intoxicação por Baccharis coridifolia. In: RIETCORREA, F., MÉNDEZ, M.C., SCHILD, A.L. Intoxicação por plantas e micotoxicoses em animais domésticos. Montevideo : Hemisferio Sur, 1993. v.1, p.159-169.

FRASER, C.M. Manual Merck de veterinária. 6.ed. São Paulo : Roca, 1991. 1803p

GAVA, A. Intoxicação por Prunus sellowii. In: RIET CORREA, F., MÉNDEZ, M.C., SCHILD, A.L. Intoxicação por plantas e micotoxicoses em animais domésticos. Montevideo : Hemisferio Sur, 1993. .1, p.285-289

KINGSBURY, J.M., HILLMAN, R.B. Pokeweed (Phytolacca) poisoning in a dairy herd. Cornell Vet, v.55, p.534-538, 1964

LANGOHR, I.M., GAVA, A., BARROS, C.S.L. Intoxicação por Baccharidastrum triplinervium (Asteraceae) em bovinos. Relato de caso. In: ENCONTRO NACIONAL DE PATOLOGIA VETERINÁRIA (ENAPAVE), 9, 1999, Belo Horizonte. Anais... Belo Horizonte : FEP-MVZ, 1999. p.142.

LEWIS, H.W., SMITH, P.R. Poke root herbal tea poisoning. J Am Vet Med Assoc, v.242, n.25, p.1759-1760, 1979.

LORENZI, H. Plantas daninhas do Brasil. 2 ed. Nova Odessa: Plantarum, 1991. Cap. s/n: Phytolacca americana: $337 \mathrm{p}$.

McCAIN, J.W., GOETZ, R.J., JORDAN, T.N. Indiana plants poisonous to livestock and pets. Indiana : Purdue University, 1985. p.83-84.

MUGERA, G.M. Phytolacca dodecandra L'herit toxicity in livestock in Kenya. Bull Epizoot Dis Afr, v.8, p.41-43, 1970.

OEHME, W.F. Distúrbios causados pelas toxinas. In: SMITH, P.B. Tratado de medicina interna de grandes animais. São Paulo : Manole, 1994. v.2, Cap.50, p.1619-1658.

PATTERSON, F.D. Pokeweed causes heavy losses in swine herd. Vet Med Small Anim Clin, v.24, p.114, 1929.

PEIXOTO, P.V., WOUTERS, F., LEMOS, R.A., $\boldsymbol{e}$ t al Phytolacca decandra poisoning in sheep in Southern Brazil. Vet Hum Toxicol, v.39, n.5, p.302-303, 1997.

STORIE, G.J., MCKENZIE, R.A., FRASER, I.R. Suspected packalacca (Phytolacca dioica) poisoning of catlle and chickens. Aust Vet J, v.69, p.21-22, 1992.

TOKARNIA, C.H., PEIXOTO, P.V., GAVA, A., $\boldsymbol{e t}$ al. Intoxicação experimental por Baccharis megapotamica var. megapotamica e var. weirii (Compositae) em bovinos. Pesq Vet Bras, v.12, n.1/2, p.19-31, 1992. 